\title{
STRESS IN GLAUCOMA, FROM THEORY TO PRACTICE
}

\author{
Farah S. CONSTANTIN ${ }^{1,2} \bowtie$, Andrei E. CONSTANTIN ${ }^{3}$, Bianca M. RADU³ \\ 1 "Ovidius" University, Faculty of Medicine, Constanta, Romania \\ 2 Department of Ophthalmology, Emergency County Clinical Hospital "Sf. Apostol Andrei”, Constanta, \\ Romania \\ 3 "Carol Davila" University of Medicine and Pharmacy, Bucharest, Romania \\ Received 30 Dec 2020, Accepted 15 Febr 2021 \\ https://doi.org/10.31688/ABMU.2021.56.1.17
}

\begin{abstract}
Introduction. Glaucoma is a bilateral progressive hereditary optic neuropathy which determines the slow and irreversible destruction of the optic nerve fibres.

Cases presentation. We present two cases of primitive open-angle glaucoma developed following sustained stress. In both cases, the cause of glaucoma was the depressive disorder. Once glaucoma is installed, therapy will be continued long-life, to prevent irreversible vision damage and thus to increase the quality of life of these patients.

Conclusions. Glaucoma, as a disease with blinding potential, determines an additional stress, besides the preexisting stress, which itself is the triggering cause of the disease. The relationship between stress and increased intraocular pressure is known into practice, but it is still insufficiently researched. The relationship between elevated intraocular pressure and worsening glaucoma during the life of these patients is known, and the existence of stress leads to increased intraocular pressure. This cascade of side effects of stress leads to the aggravation of glaucomatous disease.
\end{abstract}

Keywords: primitive open-angle glaucoma, depression, intraocular pressure.

\section{RÉSUMÉ}

Le stress dans le glaucome, de la théorie à la pratique

Introduction. Le glaucome est une neuropathie optique progressive bilatérale, qui détermine la destruction progressive et irréversible des fibres du nerf optique.

Rapports du cas. Nous présentons deux cas de glaucome primitif à l'angle ouvert, qui ont progressé suite à un stress prolongé, ayant provoqué des effets secondaires sur la qualité de la vie des deux patients. Dans les deux cas, la cause de l'apparition du glaucome était l'existence d' événements personnels tristes pursuivis de dépression. Une fois installé le glaucome, la thérapie recommandée sera continuée toute la vie afin de prévenir une détérioration irréversible de la vue et assurer implicitement la qualité de vie de ces patients. Conclusions. Le glaucome, comme maladie à potentiel d'aveuglement détermine un stress supplémentaire au stress préexistant chez ces patients, dont la cause de déclenchement de la maladie a été justement le stress. La relation entre le stress et l'augmentation de la pression intraoculaire est connue dans la pratique médicale, mais elle est insuffisamment étudiée. On connait bien la relation entre les valeurs élevées de la 


\author{
Abbreviations list: \\ $\mathrm{RE}$ - right eye \\ LE - left eye \\ VARL - visual acuity right and left eyes \\ IOP - intraocular pressure \\ Dsf - spherical diopters \\ Dcyl - cylindrical diopters
}

\section{INTRODUCTION}

The pathophysiological mechanisms through which glaucoma develops are not completely known. The risk factors are family history, elevated intraocular pressure, eye trauma, diabetes mellitus, arterial hypertension, cardiovascular diseases, severe myopia or hypermetropia.

Stress is a biological response of the body to the actions of physical, biological, psychological or chemical factors from the external environment. This response consists of morpho-functional changes, especially of endocrinological nature, which cause changes in homeostasis ${ }^{1}$. It has been shown that stress can also result from positive events. Thus, stress is defined as eustress (caused by positive stressors, such as marriage, career progression, leave) and distress (resulting from negative stressors, such as the death of a loved one, receiving an unfavorable medical diagnosis, incarceration, personal trauma) ${ }^{2}$. Physical stressors may be extreme temperatures, radiation, intense physical exercises, trauma or surgery. Biological factors are represented by viral, bacterial, parasitic or fungal infections, which determine the activation of the immune system. Chemical stressors are toxic substances released accidentally or not into the environment. The last category of stressors includes the psychological ones, that determine a subjective cognitive response and result in different actions on the individual's body².

The biological mechanisms described in stress are represented by changes in serum hormone levels. These mechanisms work through the hypothalamus, which sends efferents to the rest of the body through the sympathetic adrenomedullary axis and the hypothalamic-pituitary-cortico-adrenal axis ${ }^{3}$. Some of these changes cause high blood pressure, a risk factor for glaucoma. Through the sympathetic adrenomedullary axis, the medullary-adrenal gland releases catecholamines (epinephrine and norepinephrine) $)^{2,4}$. This causes an increase in blood pressure, as well as vasospasm, which can affect the axonal function of the retinal ganglion cells ${ }^{5}$. pression intraoculaire et l'aggravation de la maladie du glaucome tout au long de la vie de ces patients, et l'existence du stress conduit à l'augmentation de la pression intraoculaire. Cette succession d'effets secondaires du stress se trouve à la base de l'aggravation de la maladie du glaucome.

Mots-clés: glaucome primitif à l'angle ouvert, dépression, pression intraoculaire.

In chronic stress, by stimulating the adenohypophysis on the hypothalamic-pituitary-adrenal cortex, adrenocorticotropin $(\mathrm{ACTH})$ is released, which causes the activation of the adrenocortical gland. The effects of activating the adrenocortical gland are the increased levels of mineralocorticoids and glucocorticoids ${ }^{2}$. By increasing glucocorticoids, especially in the trabecular meshwork, its resistance to aqueous humor drainage increases, causing increased intraocular pressure $^{5}$. In addition to the effect on the trabecular meshwork, an increase in glucocorticoid levels causes an increase in blood pressure. Chronic stress causes an increase in the release of vasopressin from the neurohypophysis, and this increased secretion causes an increase in blood pressure, through its action on the kidneys ${ }^{6}$.

We present two patients with mental distress as the only trigger for glaucoma.

\section{FIRST CASE PRESENTATION}

We present the case of a 45-year-old patient from the urban environment, who presents to an ophthalmological control for reading disorders, temporal headache with occipital irradiation, view of colored circles around light sources, with intermittent evolution in the last 10 months. The patient affirms that these symptoms were triggered by a tragic personal event, resulting in anxiety, insomnia, fear, mental lability. The psychiatric examination established the diagnosis of depressive disorder, but the patient refused the psychiatric treatment.

The ophthalmological examination reveals:

- Visual acuity right and left eyes (VARL) 1 without correction.

- Intraocular pressure (IOP) determined with Goldmann aplanotonometer: IOP right eye 32 $\mathrm{mmHg}$, IOP left eye $30 \mathrm{mmHg}$.

- Normal eye motility in all mono and binocular directions.

- Biomicroscopic examination of the anterior pole shows both eyes with normally colored conjunctiva, smooth, glossy, transparent cornea, medium depth anterior chamber, iris with normal-looking 
stroma, well-represented pigmented collarette, round, reactive pupils and transparent lens.

- Examination of the fundus by direct ophthalmoscopy in both eyes reveals flat papilla, with clear contour, slightly deep excavation, cup/ disc ratio 0.2 , neuro-retinal area of normal appearance, central vessels slightly deviated nasally and macula with present foveolar reflex.

Complementary explorations:

- Autorefractometry:

Right eye (RE): +0.50 Dsf $<>+0.25$ Dcyl ax 60

Left eye (LE): +0.75 Dsf

- Computerized visual field (Fig. 1, 2):

RE: multiple relative and absolute paracentral, superior-temporal and superior-nasal scotomas; relative central and pericentral scotomas.

LE: multiple paracentral relative scotomas in all quadrants, central and pericentral; absolute scotomas disseminated paracentral superior-nasal and superior-temporal.

- Indirect gonioscopy performed with Goldmann lens: wide open angle

- B-mode eye ultrasound was performed to rule out intraocular formations that could have increased intraocular pressure. Normal ultrasound, free vitreous, echo-transparent and attached retina were found in both eyes.

The data from history, corroborated with ophthalmological examination, guided to the following diagnosis: both eyes primitive glaucoma with newly discovered open angle, both eyes presbyopia, depressive disorder.

\section{Second CASE PREsentation}

A 48-year-old patient from the urban environment presented to ophthalmological examination for reading disorders, temporal headache with occipital irradiation, eye pain, which appear occasionally, but relatively periodically. The patient affirms that these symptoms occurred intermittently, after a negative personal event lasting for 2 years, resulting in anxiety, insomnia and mental instability (depressive disorder). The patient accepted only treatment for insomnia, with Zopiclone $7.5 \mathrm{mg}$ per day.

The ophthalmological examination revealed:

- Visual acuity: VARL 2/3 without correction, 1 with own correction (-0.50 Dsf).

- IOP determined with Goldmann aplanotonometer: IOP right eye $27 \mathrm{mmHg}$, IOP left eye $28 \mathrm{mmHg}$.

- Normal eye motility in all directions monocular and binocular.

- Biomicroscopic examination of the anterior pole showed both eyes with normally colored conjunctiva, smooth, glossy, transparent cornea, normal depth anterior chamber, iris with normal-looking stroma, well-represented pigmented collarette, round, reactive pupils and transparent lens.

- Examination of the fundus of the eye, ophthalmoscopy in both eyes, revealed flat papilla, with clear contour, slightly deep excavation, cup/ disc ratio 0.3 , neuro-retinal area of normal appearance, central vessels slightly deviated nasally and macula with present foveolar reflex.

Complementary explorations:

- Autorefractometry:

RE: $-0.50 \mathrm{Dsf}$

LE: -0.50 Dsf

- Computerized visual field (Fig. 3,4):

RE: isolated paracentral inferior-nasal, inferior-temporal isolated scotomas and pericecal relative scotomas.

LE: relatively isolated paracentral superior-temporal scotoma and relatively isolated pericecal scotoma.

- Indirect gonioscopy performed with Goldmann lens: wide open angle.

- B-mode ocular ultrasound was performed to rule out the existence of intraocular formations that could have increased intraocular pressure. Normal ultrasound, free vitreous, echo-transparent and attached retina were found in both eyes.

The data from history, corroborated with the overall ophthalmological examination, guided to the following diagnosis: both eyes primitive glaucoma with newly discovered open angle, both eyes myopia, both eyes presbyopia, depression.

In both cases we decided to delay the initiation of ophthalmological treatment and monitor the following parameters: monthly determination of intraocular pressure, computerized visual field after 6 months and psychiatric monitoring of the patients by the answer to the questionnaire on negative stress, namely the frequency of insomnia, sweating, sadness and changes in blood pressure. Throughout the period, insomnia was persistent, sweating settled periodically, episodes of sadness were daily and blood pressure values were moderately high. The results were as follows: the ocular tension remained high, approximately the same values and there was a change in the perimeter parameters, namely the scotomas have multiplied. After 3 months, antiglaucoma treatment with prostaglandin analogues (latanoprost 1 eye drop every 24 hours) was initiated. Psychiatric treatment was added with Agomelatinum $25 \mathrm{mg}$ daily. The evolution of the patients was favorable: the intraocular pressure decreased considerably, which led to the preservation of the visual field. 


\begin{tabular}{|c|c|c|c|c|c|c|c|}
\hline \multirow{2}{*}{\multicolumn{2}{|c|}{$\begin{array}{l}\text { OCULUS Centerfield } \\
\text { Version: } 3.18 \mathrm{r} 971\end{array}$}} & & ame: & & & \multicolumn{2}{|l|}{ Right } \\
\hline & & \multicolumn{2}{|c|}{ Date of bith: } & \multicolumn{4}{|c|}{ ID: } \\
\hline \multicolumn{2}{|c|}{ Program: Glaucoma Threshold } & Stimulus: & III, white & Pupil: & $3.1 \mathrm{~mm}$ & \multicolumn{2}{|c|}{ Date of exam.: 2020/07/17 } \\
\hline \multicolumn{2}{|c|}{ Area: $\quad 30.2$} & \multicolumn{2}{|c|}{ Background: $10 \mathrm{~cd} / \mathrm{m}^{2}$ [31.4 asb] } & \multicolumn{2}{|c|}{ Presentation time: $0.2 \mathrm{sec}$} & Time: & $13: 43: 03$ \\
\hline \multicolumn{2}{|c|}{ Strategy: Fast threshold } & Correction: & No & Speed: & Adaptive & Age: & 71 \\
\hline Fixation: & Heil Krakau & $0 \mathrm{~dB}:$ & $3180 \mathrm{~cd} / \mathrm{m}^{2}$ (simulated) & & & Abs.loss: & 4 \\
\hline Fixationcheck: & $11 / 12$ (92\% Losses) & & & & & Rel.loss: & 18 \\
\hline False positive: & $3 / 24$ [13\% Error] & & & & & & \\
\hline
\end{tabular}

Presented dots: 337

Duration: 07:45

Re-Examination: No

FOV: $\quad 26$
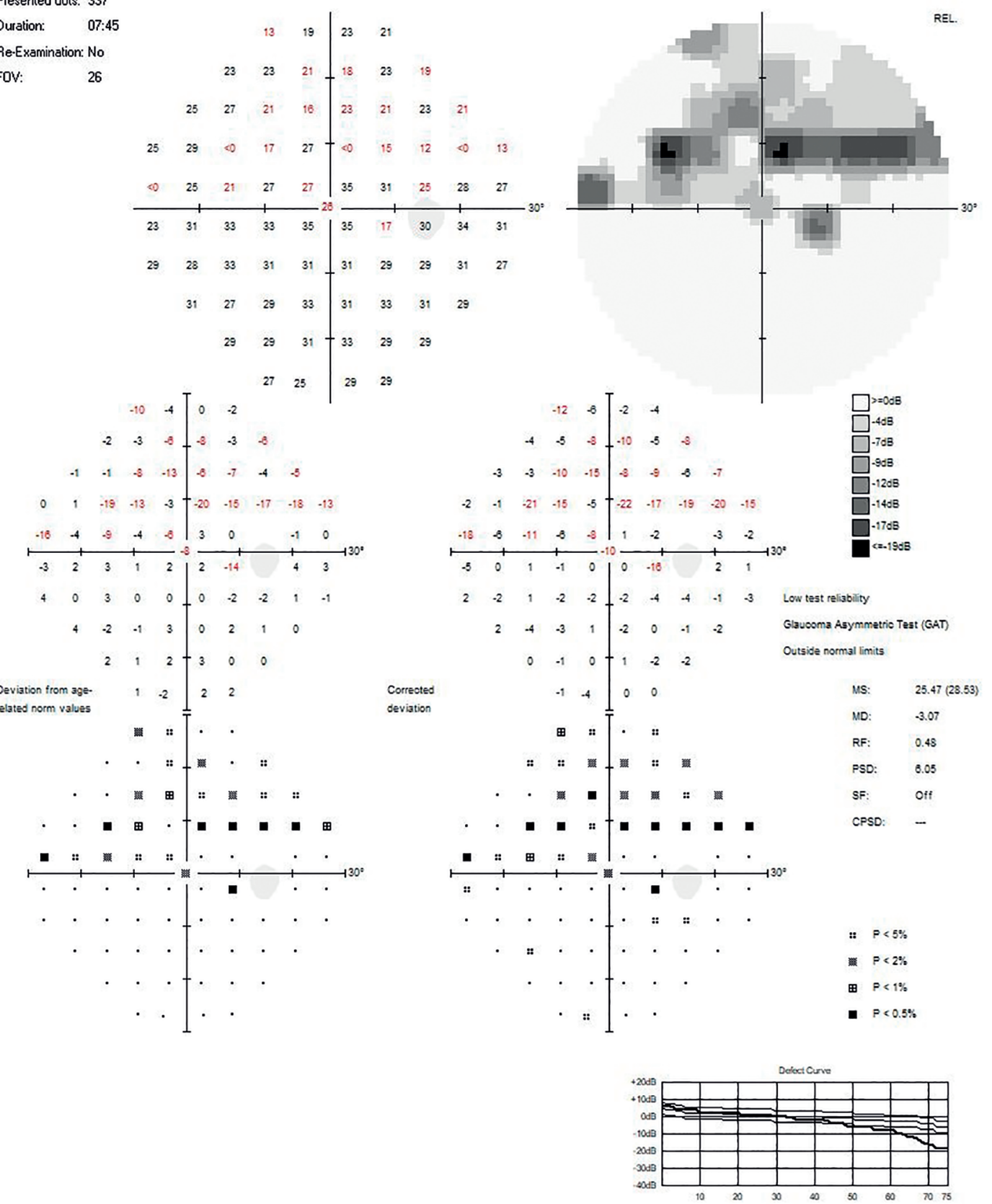

Figure 1. Computerized visual field on the right eye (first case) - multiple relative and absolute paracentral, superior-temporal and superior-nasal scotomas; relative central and pericentral scotomas 
Archives of the Balkan Medical Union

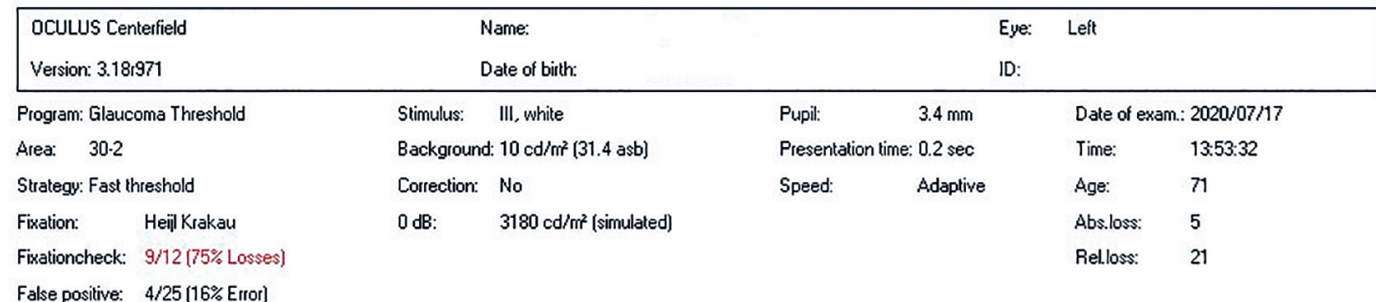

Presented dots: 329

Duration: 08:01

Re-Examination: No

FOV: $\quad 27$
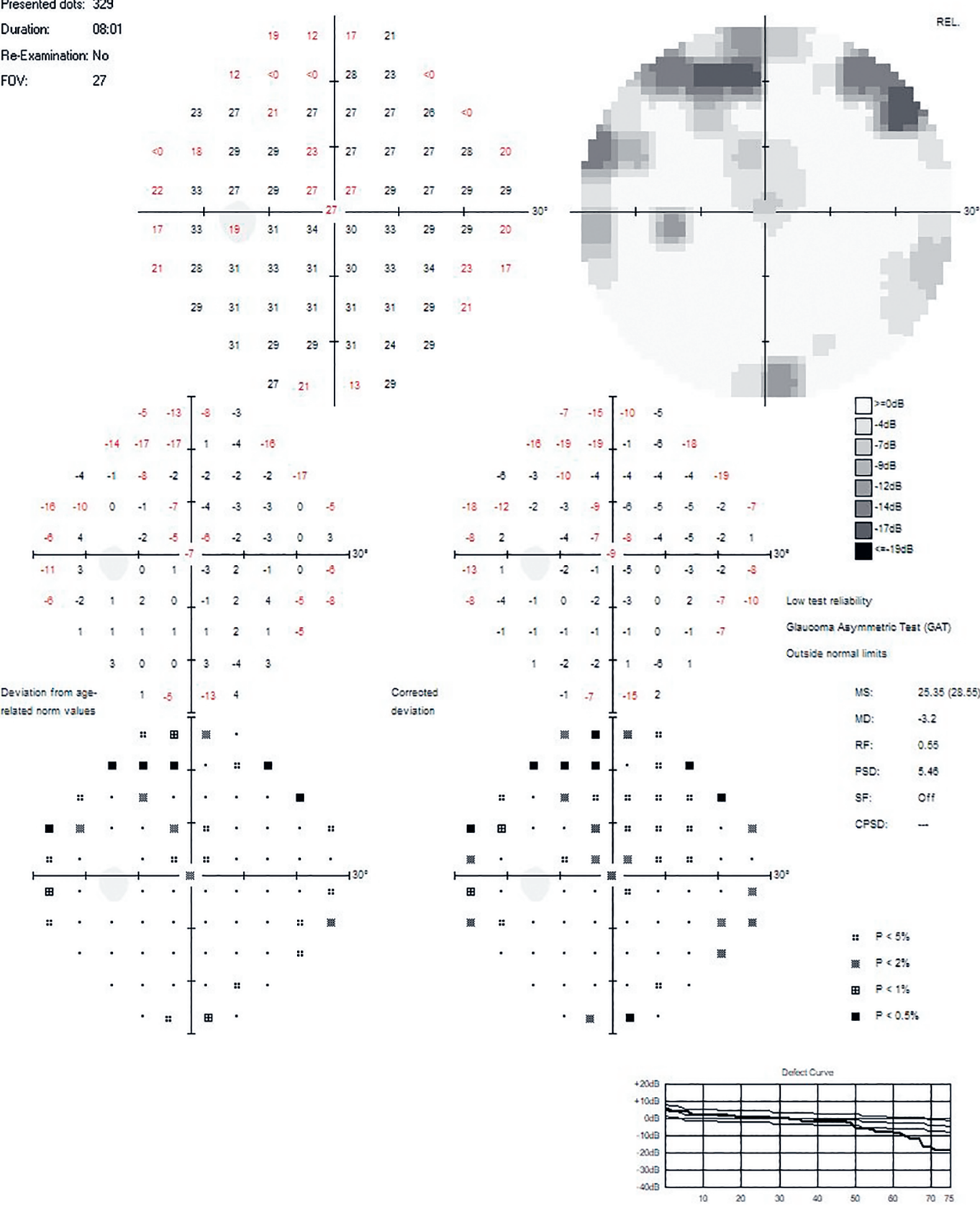

Figure 2. Computerized visual field on the left eye (first case) - multiple paracentral relative scotomas in all quadrants, central and pericentral; absolute scotomas disseminated paracentral superior-nasal and superior-temporal 


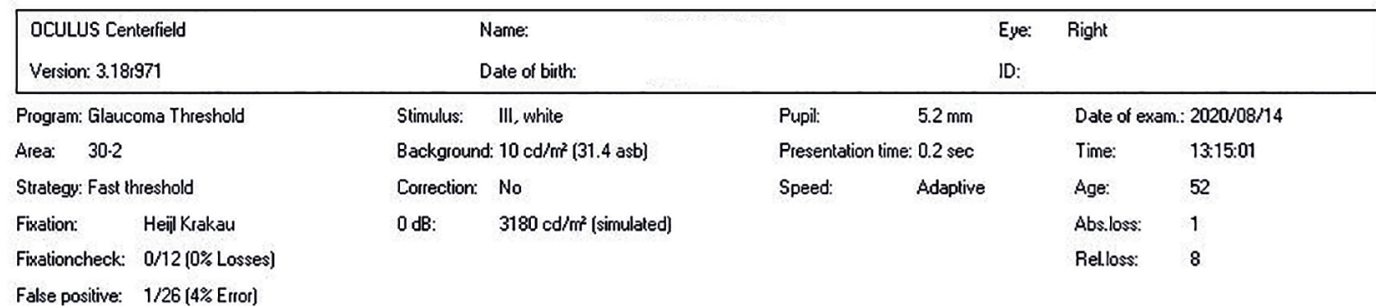

Presented dots: 347

\begin{tabular}{lll|ll} 
Duration: $\quad 07: 44$ & 27 & 25 & 27 & 25 \\
Re-Examination: No & & &
\end{tabular}

FOV: $\quad 34$
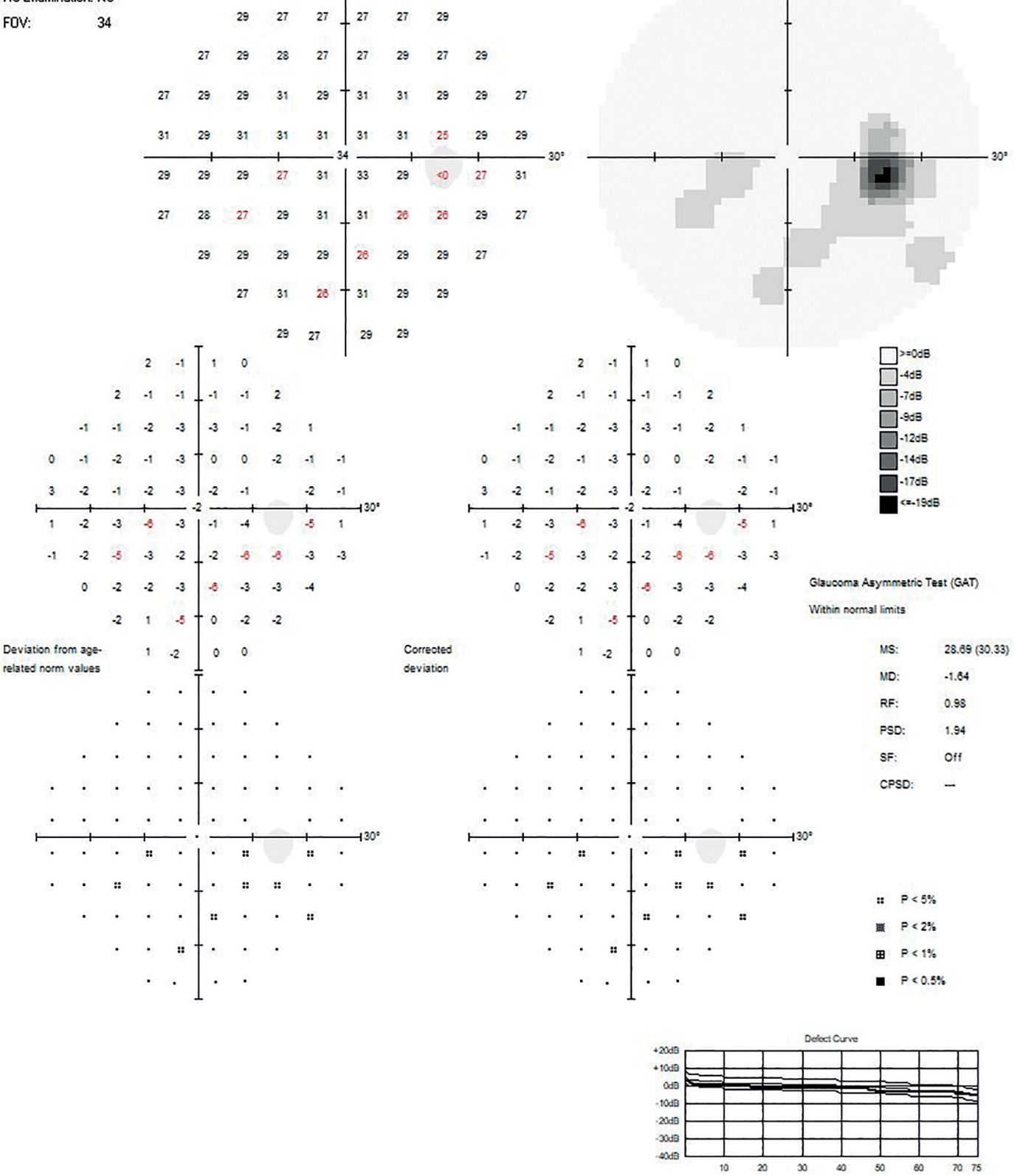

Figure 3. Computerized visual field on the right eye (second case) - isolated paracentral inferior-nasal, inferior-temporal isolated scotomas and pericecal relative scotomas 
Archives of the Balkan Medical Union

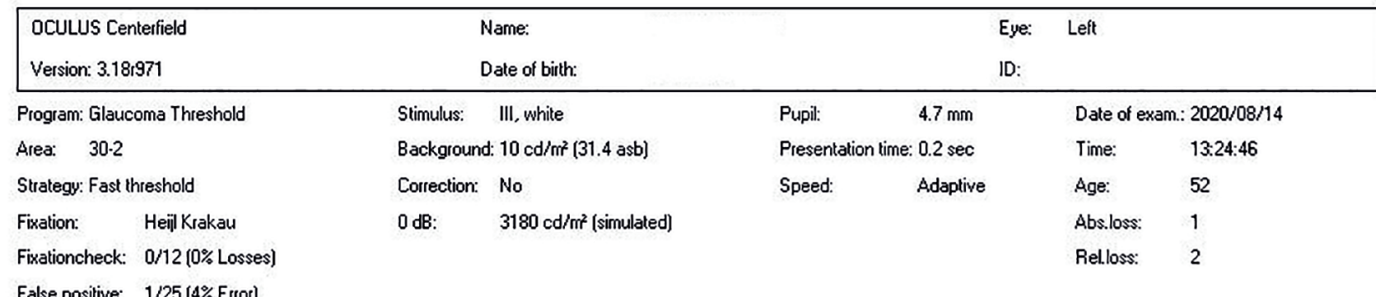

$1 / 25$ (4\% Error)

Presented dots: 337

Duration: $\quad 07: 34$

Re-Examination: No

FOV: $\quad 33$
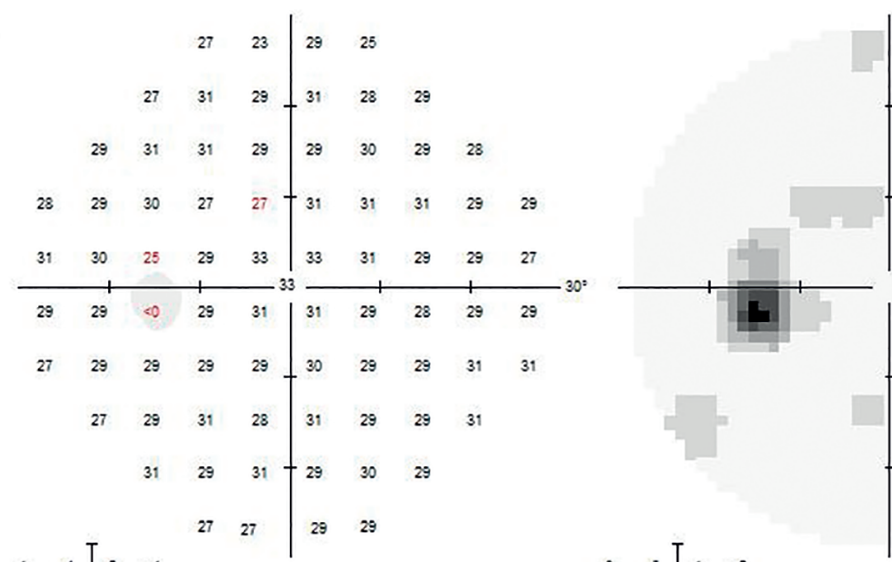

REL.
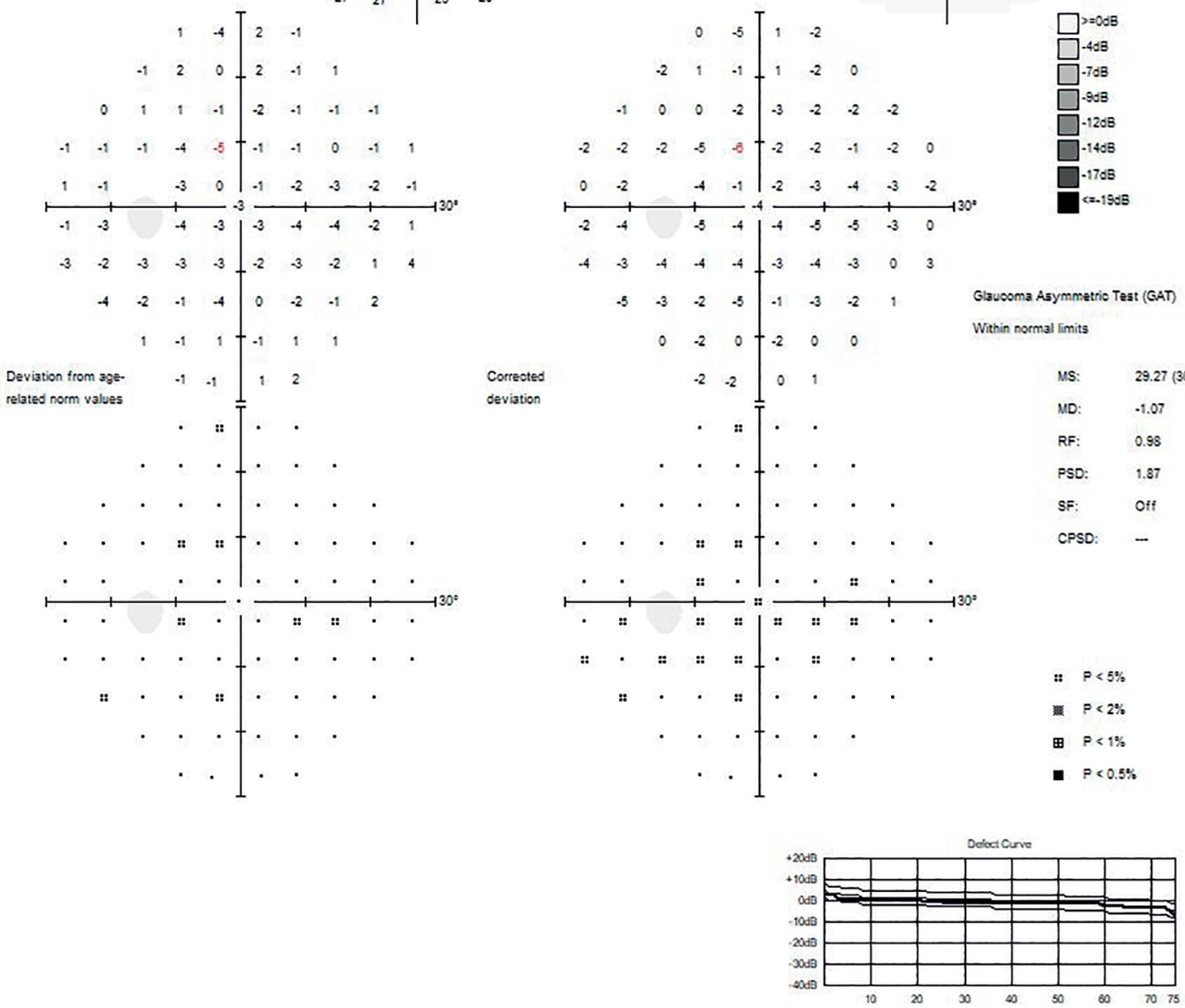

Figure 4. Computerized visual field on the left eye (second case) - relatively isolated paracentral superior-temporal scotoma and relatively isolated pericecal scotoma 


\section{Discussion}

In the cases presented, mental stress for a long time determined the appearance of perimeter defects with negative progression over 6 months, confirming that stress determines the progression of primitive open-angle glaucoma.

In 1818, Dermour referred to the personality of glaucoma patients and mentioned them as having psycho-emotional tensions, and the main feature that characterizes them is nervousness ${ }^{7}$. The correlation between insomnia and intraocular pressure values, along with circadian effects of hormones on the dynamics of the aqueous humor, cause an increase in intraocular pressure during night ${ }^{8,9}$. Stress-induced sleep disorders are considered risk factors in the progression of glaucoma. Insomnia causes hyperreactivity of the sympathetic nervous system, having a role in modulating the response to the association of other stressors?

Psychological stress has effect on body temperature, blood pressure and blood circulation, which causes fluctuations in the perfusion of optic nerve ${ }^{4}$. Under the action of stress, there is an increased release of adrenaline and tumour necrosis factor (TNF)-alpha proinflammatory substances and higher amounts of cortisol are released, which can increase the production of aqueous humor, with increasing intraocular pressure, cortisol being a mediator of stress-induced immune disorders ${ }^{5}$.

Mental stress negatively influences the evolution of primitive open-angle glaucoma and an improvement in the patient's psycho-emotional status could lead to a decrease in intraocular pressure ${ }^{10}$. A study performed in the Glaucoma Center of the Cluj-Napoca Ophthalmology Clinic, Romania, published in 2011, found a significant correlation between physical or mental stress and increased intraocular pressure ${ }^{11}$. Patients who have suffered from mental stress for a long time and did not have drug-compensated intraocular tensions developed visual field lesions. All patients who were decompensated because of short-term stress had compensated tension after the disappearance of stress, without the need to change their treatment ${ }^{11}$.

A study conducted in Germany and published in 1996 found that experimentally-induced mental stress increased the intraocular pressure in a group of glaucoma-free students who presented moderate increases in intraocular pressure during the exam session, because of stress. Another study by the same researchers showed that exposure to a mental stress factor led to a significant increase in intraocular pressure in a group of patients with primitive open angle glaucoma ${ }^{12}$.

The association between nocturnal physiological decrease in blood pressure and increase in intraocular pressure $e^{13}$ has a double impact on blood flow to the optic nerve, and it is known that hypoperfusion of the optic nerve head is considered a risk factor for the progression of glaucomatous disease ${ }^{9}$. All these ultimately lead to increased intraocular pressure, which is a proven risk factor for the progression of irreversible damage of the optic nerve.

\section{Conclusions}

The interdisciplinary collaboration with a psychologist and/or psychiatrist is necessary to improve patients' quality of life, that would slow the progression of glaucoma. Glaucoma, as a disease with blinding potential, causes additional stress to preexisting stress in these patients whose disease-triggering cause was stress itself. The additional source of anxiety and stress is the awareness of the effects of glaucoma on vision, associated with the feeling of helplessness in the face of a disease that can cause blindness.

\section{Author Contributions:}

F.S.C. was responsible for the diagnostic procedures, clinical diagnosis, and treatment decisions. F.S.C., A.E.C. and B.M.R. wrote the manuscript. All authors have read and agreed to the published version of the manuscript.

\section{Compliance with Ethics Requirements:}

"The authors declare no conflict of interest regarding this article"

"The authors declare that all the procedures and experiments of this study respect the ethical standards in the Helsinki Declaration of 1975, as revised in 2008(5), as well as the national law. Informed consent was obtained from all the patients included in the study"

"No funding for this study"

\section{Acknowledgements:}

None

\section{References}

1. https://www.ncbi.nlm.nih.gov/pmc/articles/PMC3079864/ (Accessed on October 4, 2020)

2. American Psychiatric Association, Diagnostic and Statistical Manual of Mental Disorders, $5^{\text {th }}$ Ed., Washington DC, 2013.

3. https://www.ncbi.nlm.nih.gov/pmc/articles/PMC6408777/ (Accessed on October 4, 2020)

4. Pennebaker J.W., Writing about emotional experiences as a therapeutic process, Psychological Science, 1997, 8:162-166.

5. Méndez-Ulrich JL, Sanz A. Psycho-ophthalmology: contributions of health psychology to the assessment and treatment of glaucoma. Psychology E Health. 2017;32(3):330-342.

6. https://www.ncbi.nlm.nih.gov/pubmed/17451068 (Accessed on October 4, 2020) 
7. Michelle C, Diana R, Ingrid J, et al. Personality type of the glaucoma patient. J Glaucoma. 2007; 16(8): 649-654.

8. Chiselita D, Motoc I, Danielescu C. Day and night fluctuations in intraocular pressure and systemic blood pressure in glaucomatous and non-glaucomatous patients. Rev Oft. 2008; LII(1):119-125.

9. Jihui Z, Ronald C, Alice P, et al. Relationship of sleep quan tity and quality with 24-hour urinary catecholamines and salivary awakening cortisol in healthy middle-aged adults. Sleep. 2011;34(2): 225-233.
10. Marc A, Stan C. The influence of psychical and physical stress in open angle glaucoma evolution. Rev Oft. 2013;LVII(2):60-66.

11. Stan C, Tarziu D, Lupascu S, Iuga M. A new risk factor in glaucoma? Oftalmologia. 2011; 55(1): 74-76.

12. Gert K, Ilse S, Heidrum M. Stress reactivity of intraocular pressure after relaxation training in open-angle glaucoma patients. Journal of Behavioral Medicine. 1996;19(6): 587-597.

13. Coroi MC, Bungau S, Tit M. Prezervatives from the eye drops and the ocular surface. Rom J Ophthalmol. 2015;59(1):2-5 